\title{
Selection of common edible herbs which inhibit aflatoxin production or fungal growth
}

\author{
Chinaphuti, A. and Aukkasarakul, S. \\ Post harvest and Processing Research and Development Office, \\ Department of Agriculture, \\ (Chatuchark, Bangkok 10900 Thailand.)
}

\begin{abstract}
Aflatoxin is a toxic secondary metabolite produced by certain strains of Aspergillus flavus. The contamination of aflatoxin occurred in a wide variety of food and feed and has been implicated in a range of human and animal diseases. Because it is mainly concerning with human consumption, hence the method used for controlling aflatoxin should be safe to human. The aim of this study was to select the varieties of edible herbs which commonly grow in Thailand and can inhibit aflatoxin production or fungal growth in order to use as aflatoxin control agent in food and feed. Generally, most herbs were known to inhibit fungal growth. In this study we tried to select herbs which directly do inhibit aflatoxin production aside from growth inhibition.

Sixteen varieties of edible herbs which commonly grow in Thailand were selected for the tests. Tip culture method was employed to characterize the efficiency of herb extracts to inhibit aflatoxin production or mycerial growth. Amount of aflatoxin production and mycerial weight of each treatment were determined as percent inhibition from control. Six varieties of herbs were found to cause high percentage of aflatoxin production inhibition (64-99 \%) whereas percent inhibition of mycerials weight was low or no inhibition. They were Pluyllanthus amarus, Zingiber afficinale, Thuybergia taurifolia, Occimum basilicum, Boesenbergia pandurata and Tumaric sp. The other 5 varieties Syzyglum aromaticum, Occimum tenuiflorum, Cymbopogon citrates, Alpinia nigra and Allium sativum gave high percentage of mycerial weight inhibition(50-70\%) which enhanced to have high percentage of aflatoxin inhibition(80-99\%). The effectiveness of these common herbs can be utilized as biological control of aflatoxin production or fungal growth in food and feed.
\end{abstract}

Key words : aflatoxin, herbal extract, inhibition

\section{Introduction}

Aflatoxins are well known mycotoxins for their potent carcinogenicity. They are produced by certain strains of Aspergillus flavus and $A$. parasiticus. Aflatoxin $\mathrm{B}_{1}$ is the most toxic among four natural aflatoxins, $\mathrm{AFB}_{1}, \mathrm{FB}_{2}, \mathrm{AFG}_{1}$ and $\mathrm{AFG}_{2}$. Whereas nearly all $A$. parasiticus produce aflatoxins B and G, toxigenic strain $A$. flavus produces only B aflatoxin ${ }^{1)}$. $A$. flavus is isolated more frequently than $A$. parasiticus from most crops.

Since aflatoxins have been discovered in $1960^{\mathrm{s}}$, many studies have been done on detection of toxin in many varieties of food and feed commodities. Control and management 
of aflatoxin were the most important issues of concern ${ }^{2)}$. Unquestionably, prevention is the best method for controlling aflatoxin contamination. If prevention method is not function well, decontamination procedures should be designed to remove or inactivate the toxicant in food and feed. The methods for both prevention and decontamination are based on chemical, physical and biological means ${ }^{3)}$.

Approximately 100 compounds as chemical mean of control demonstrate to inhibit aflatoxin production, but most appear to do so by inhibiting fungal growth ${ }^{4}$. The mode of action of most compounds which inhibit aflatoxin production is unknown. However, there are two extensive studied inhibitors of aflatoxin synthesis dichlovos and caffeine. Dicholovos, an organophosphorous insecticide having the chloline esterase inhibitory activity was found to show effect on aflatoxin biosynthesis pathway but not growth ${ }^{5)}$. Caffeine inhibits both growth and aflatoxin production. The possible mode of action for inhibition by caffeine is the inhibition of glucose up take which is the requirement of aflatoxin biosynthesis ${ }^{6)}$. Up to present, insecticide, spices and plant extract were screened for prevention of aflatoxin contamination in food and feed, but non of them has practically been used ${ }^{7}$.

In Thailand, many varieties of herbal plants have been extensively used for treating diseases from an ancient time and are still the principle source of medicines today. Some of those herbal plants were used as daily cooking ingredients such as garlic, basil leaves and ginger. Park (1993) ${ }^{8}$, mentioned that the acceptance of given decontamination or prevention procedures for mycotoxins contamination, including that which should not produce or leave toxic residue in food and feed. Hence, in the present studies, we screened common edible herbs, which used as human consumption as food and medicines, and are easy to grow in various locations and low cost, to inhibit $A$. flavus growth and also aflatoxin biosynthesis.

\section{Material and methods}

Selection of edible herbs Sixteen varieties of common edible herbs which generally used as cooking ingredients and medicines were selected to used in this studies. They are Andrographis paniculata, Pluyllanthus amarus, Hibicus sabdariffaa, Syzygium aromaticum, Cissus guadrangularis, Zingiber officinale, Dipen samentosum, Allium ascalonicum, Boessenbergia pandurata, Turmaric sp., Allium sativum, Thugbergia laurifolia, Occimum tenuiflorum, Occimum basilicum, Cymbopogon citratus and Alpinia nigra.

Extraction of selected herbs Each selected herbs was simply extracted and diluted with distilled water. One hundred grams of clean sample was chopped into small pieces, then grinding with blender. Ground sample was directly squeezed through the sheet cloth. Subsequently, crude extract was diluted with distill water to 1:1, 1:2 and 1:4. Each dilution was filtered for bacteria. The filtrate was ready to test in the experiments.

Screening of edible herbs for fungal growth inhibition Pour plate method was employed to determine the effectiveness of herbal crude extracts at various concentration to inhibit fungal growth. Nine micro liter of DG18 medium was poured to the plate then added $1 \mathrm{~mL}$ of herbal extract. After the mixed medium became solid, agar plug of A. flavus was placed at the center of petri dish. Five replications were done at each concentration $(1,1: 1,1: 2$ and1:4) of herbal extract and control (without herbal extract). The plate were then incubated at room temperature for 7 days. Dimension of $A$. flavus colony was measured in comparison to control then percentage of reduction was calculated.

Screening of edible herbs for inhibitory to aflatoxin production and fungal growth Tip culture method according to Yabe et al., (1988) ${ }^{9}$ ) was used in this experiment. Micropipet tip $(1 \mathrm{~mL})$ was used as the culture vessel for the fungal growth. After small amount of quartz wool was stuffed at the end of the tip, the tip was weighed. Then, the tip was putted onto a glass tube and the tip was covered with an aluminium cap. After autoclaving, the tip bottom 
was sealed with parafilm. The herbal extract $(100 \mu \mathrm{L})$ and YES medium $(150 \mu \mathrm{L})$ were added into the tip, and the spore suspension of $A$. flavus $(5 \mu \mathrm{L})$ was then inoculated. After 4 days cultivation at room temperature, parafilm was removed from the bottom of the tip and then whole set was centrifuged at $20,000 \mathrm{rpm}$ for $30 \mathrm{sec}$. The culture medium passed through the quartz wool, whereas the mycelia remained in the tip. The aflatoxin $B_{1}$ in the medium was analyzed by ELISA. The remaining tip containing the fungus mycelium was weighed. Percentage of growth inhibition and aflatoxin $B_{1}$ inhibition were calculated. Five replications of each herbal extract concentration and control were done.

\section{Results and discussion}

Screening of edible herbs for fungal growth inhibition The dimension of $A$. flavus colonies at each herbal extract concentration were measured. Allium ascalonicum, Allium sativum, Cissus, quadrangularis, Occimum basilicum and Occimum tenuiflorum gave the high percentage of growth reduction more than $50 \%$ at every concentration $(1: 0,1: 1,1: 2$ and 1:4) of the extracts (Table 1). No fungal growth appeared on the medium containing Allium sativum extract at the concentration of 1:0, 1:1 and 1:2 (Fig. 1). The extract of Cymbopagon citratus, Syzygium aromaticum and Zingiber officinalis exhibited the fungal growth inhibition only at the high concentration (1:0 and 1:1) Low percentage of growth inhibition was found in Andorgraphis paniculata, Hibicus sabdariffa and Turmeric sp.

Table 1. Percentage of colony dimension reduction of Aspergillu flavus when inoculated on agar containing herbal extract at various concentrations.

\begin{tabular}{|c|c|c|c|c|}
\hline & \multicolumn{4}{|c|}{ Herbal extract concentration } \\
\cline { 2 - 5 } Herbs & $1: 0$ & $1: 1$ & $1: 2$ & $1: 4$ \\
\hline Allium ascalonicum & 57.14 & 55.10 & 53.06 & 57.14 \\
Allium sativum & 100 & 100 & 100 & 56.25 \\
Alpinia nigra & 39.58 & 35.41 & 41.66 & 29.16 \\
Andrographis paniculata & -37.73 & -9.43 & 0 & 1.88 \\
Boesenbergia pandurata & 34.78 & 33.33 & 33.33 & 24.63 \\
Cissus guadrangularis & 68.42 & 71.05 & 68.42 & 71.05 \\
Cymbopagon citrates & 65.21 & 71.01 & 47.82 & 44.96 \\
Dipen samentosum & 40.74 & 35.18 & 46.29 & 27.77 \\
Hibiscus sabdariffa & 9.61 & 5.76 & 9.61 & -3.84 \\
Occimum tenuiflorum & 64.28 & 64.28 & 60.71 & 66.07 \\
Occimum basilicum & 66.07 & 71.42 & 64.28 & 66.07 \\
Phyllanthus amarus & 11.11 & 24.00 & 25.92 & 16.66 \\
Syzygium aromaticum & 100 & 59.61 & 26.92 & 7.69 \\
Thuybergia laurifolia & 36.36 & 30,90 & 23.63 & 16.36 \\
Turmeric sp. & 5.45 & 10.90 & 12.72 & 27.72 \\
Zingiber officinale & 50.76 & 13.84 & 24.61 & 12.30 \\
& & & & \\
\hline
\end{tabular}

* Data average from 5 replications 


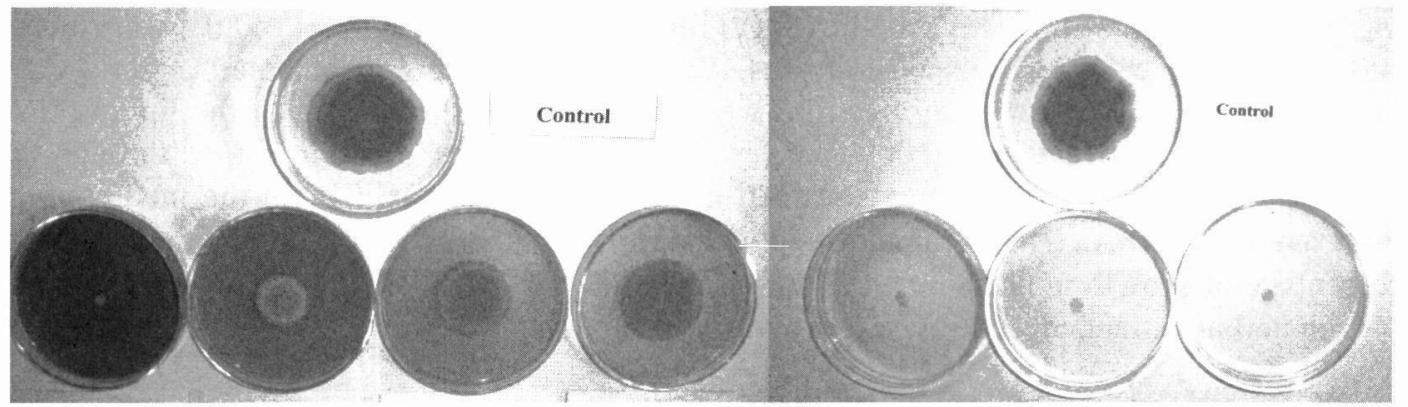

Fig. 1 Inhibition of Aspergillus flavus growth at 7 days old on DG 18 medium containing various concentrations of herbal extracts of Syzygium aromaticum and Allium sativum

\section{Screening of edible herbs for inhibitory to aflatoxin production and fungal growth}

Table 2. Effect of herbal extracts at various concentration on percent mycerial growth inhibition of Aspergillus flavus and percent aflatoxin $\mathrm{B}_{1}$ inhibition when tested by Tip culture method

\begin{tabular}{|c|c|c|c|c|c|c|c|c|}
\hline \multirow{3}{*}{ Herbs } & \multicolumn{8}{|c|}{ Concentration of herbal extracts } \\
\hline & \multicolumn{2}{|c|}{$1: 0$} & \multicolumn{2}{|c|}{$1: 1$} & \multicolumn{2}{|c|}{$1: 2$} & \multicolumn{2}{|c|}{$1: 4$} \\
\hline & $\% \mathrm{MI}^{*}$ & $\% \mathrm{AI} * *$ & $\% \mathrm{MI}$ & $\% \mathrm{AI}$ & $\% \mathrm{MI}$ & $\% \mathrm{AI}$ & $\% \mathrm{MI}$ & $\%$ AI \\
\hline Allium ascalonicum & 32.86 & 88.26 & 8.57 & 47.32 & 10.00 & 31.26 & -8.57 & 36.44 \\
\hline Allium sativum & 67.29 & 88.45 & 68.22 & 85.42 & 55.79 & 80.49 & 49.53 & 56.25 \\
\hline Alpinia nigra & 61.69 & 99.66 & 58.33 & 99.49 & 72.00 & 99.64 & 63.33 & 98.99 \\
\hline Andrographis paniculata & - & - & - & - & -30.43 & -20.97 & -17.39 & -14.66 \\
\hline Boesenbergia pandurata & -83.33 & 92.47 & 3.33 & 89.03 & -7.78 & 89.09 & 15.58 & 87.15 \\
\hline Cissus guadrangularis & -43.08 & 2.80 & -13.85 & 3.66 & 4.62 & 5.17 & 7.69 & 6.47 \\
\hline Cymbopagon citrates & 64.00 & 98.60 & 77.33 & 98.53 & 51.69 & 89.62 & 50.67 & 81.23 \\
\hline Dipen samentosum & 28.58 & 11.31 & -12.86 & 5.18 & -5.71 & -8.81 & 11.43 & -4.49 \\
\hline Hibiscus sabdariffa & -95.68 & 32.22 & -60.33 & 28.82 & -72.70 & 37.19 & - & - \\
\hline Occimum tenuiflorum & 48.81 & 83.23 & 57.14 & 99.86 & 61.91 & 99.77 & 57.62 & 99.61 \\
\hline Occimum basilicum & 33.33 & 99.97 & 35.24 & 99.98 & 38.10 & 99.91 & 32.38 & 99.62 \\
\hline Phyllanthus amarus & -31.95 & 58.53 & -9.26 & 51.28 & -12.96 & 64.97 & -1.85 & 69.52 \\
\hline Syzygium aromaticum & 94.57 & 96.26 & 86.96 & 96.59 & 60.87 & 98.38 & 87.53 & 95.96 \\
\hline Thuybergia laurifolia & -5.61 & 90.98 & 39.25 & 90.05 & - & - & - & - \\
\hline Turmeric sp. & -40.74 & 91.97 & -24.07 & 94.01 & -20.50 & 87.11 & 16.67 & 87.97 \\
\hline Zingiber officinale & 41.45 & 97.77 & 33.85 & 95.59 & 31.58 & 89.72 & 40.00 & 66.65 \\
\hline
\end{tabular}

$* \% \mathrm{MI}=\%$ mycecial growth inhibition, $* * \% \mathrm{AI}=\%$ Aflatoxin production inhibition

Data everage from 5 replications 
The result from tip culture method showed both for \% mycelial growth inhibition and \% inhibition of aflatoxin production. Result of \% mycelial growth inhibition from tip culture method was correlated to the result of pour plate method excepted the data of Cissus, quadrangularis which had low \% mycelial growth inhibition $(-43.08,-13.85,4.62$ and $7.69 \%$ at 1:0, 1:1, 1:2 and 1:4, respectively) in tip culture method (Table 2 ) but \% growth reduction was high in pour plate method.

Generally, if growth of $A$. flavus was inhibited or no growth, consequently, amount of aflatoxin production should be low. Zaika and Buchanan $(1987)^{4)}$ mentioned that most of the substances and compounds which have been demonstrated for inhibition of aflatoxin production appear to do so by inhibiting fungal growth. In this study, the result clearly showed the efficiency of some herbal extracts which inhibited only aflatoxin biosynthesis but not fungal growth. Those herbs were Boesenbergia pandurata and Turmeric sp.(Table 2).

From tip culture method data, the efficiency of herbal extracts can be divided into three groups by using \% mycelial inhibition and \% aflatoxin inhibition as a basis. (Table 3 )

Table 3. Groupping herbal extracts according to their efficacy to inhibit mycelial growth and aflatoxin production of Aspergillus flavus

\begin{tabular}{|c|c|c|}
\hline $\begin{array}{c}\text { Group I } \\
\% \text { mycelial inhibition }<50 \% \\
\% \text { aflatoxin inhibition }<50 \%\end{array}$ & $\begin{array}{c}\text { Group II } \\
\% \text { mycelial inhibition }<50 \% \\
\% \text { aflatoxin inhibition }>50 \%\end{array}$ & $\begin{array}{c}\text { Group II } \\
\% \text { mycelial inhibition }>50 \% \\
\text { aflatoxin inhibition }>50 \%\end{array}$ \\
\hline 1. Allium ascalonicum & $\begin{array}{c}\text { 1. Boesenbergia pandurata } \\
\text { 2. Andrographis paniculata }\end{array}$ & $\begin{array}{c}\text { 2. Occimum basilicum } \\
\text { 2. Aalium sativum }\end{array}$ \\
3. Cissus guadrangularis & 3. Phyllanthus amarus & 3. Cymbopagon citrates \\
4. Dipen samentosum & 4. Thuybergia laurifolia & 4. Occimum tenuiflorum \\
5. Hibiscus sabdariffa & 5. Turmeric sp. & 5. Syzygium aromaticum \\
\hline
\end{tabular}

Group I: \% mycerial inhibition $<50 \%$ vs \% Aflatoxin inhibition $<50 \%$ GroupII: \% mycerial inhibition $<50 \%$ vs \% Aflatoxin inhibition $>50 \%$ GroupIII: \% mycerial inhibition $>50 \%$ vs \% Aflatoxin inhibition $>50 \%$

In these studies six herbal extracts which classified into group II were obtained. Characterization of inhibitory substances of those herbs will be studied for practically application. Group III herbs were also useful for prevention and control of fungus growth and aflatoxin contamination. Practically, all the selected herbs in group II and group III are very common growing in Thailand for human consumption. Therefore, they are possibly and practically used for prevention and decontamination of aflatoxin in food and feed.

\section{References}

1) Buchanan, R. L., Lewis, D.F.: Appl. Environ. Microbiol., 47 1216-1220 (1984)

2) Council for Agricultural Science and Technology; Mycotoxins and human health. Mycotoxins economic and health risks. Report No. 116 28-35, CAST, Ames. (1989)

3) Marth,E.H., Doyle, M.P. : Food Technol., 33 81-87 (1979) 
4) Ono. M., Sakuda, S., Suzuki, A, Isogai, A.: J. Antibiotics., 50. No.2 111-118 (1997)

5) Park, D. L.: Food Technology, 92-96 (1993)

6) Pitt, J. I.: J. Food Prot., 56, 265-269 (1993)

7) Singh, R., Hsieh, D.P.H.: Arch. Biochem. Biobhys., 178, 285-292 (1977)

8) Yabe, K., Nakamura, K., Ando, K., Terakado, N., Nakajima, H., Hamazaki, T.: Appl. Environ. Microbiol., 54, 2096- 2100 (1988)

9) Zaia, L.L., Buchanan, R.L.: J. Food. Prot., 50 691-708. (1987) 